\title{
Drug prescribing during pregnancy in a central region of Italy, 2008-2012
}

\author{
Martina Ventura ${ }^{1 *}$, Alice Maraschini ${ }^{2}$, Paola D'Aloja ${ }^{2}$, Ursula Kirchmayer ${ }^{1}$, llaria Lega ${ }^{2}$, Marina Davoli ${ }^{1}$ \\ and Serena Donati ${ }^{2}$
}

\begin{abstract}
Background: Drug consumption during pregnancy is a matter of concern, especially regarding drugs known or suspected to be teratogens. Little is known about drug use in pregnant women in Italy. The present study is aimed at examining the prevalence, and to detect potential inappropriateness of drug prescribing among pregnant women in Latium, a region of central Italy.

Methods: This retrospective study was conducted on a cohort of women aged 18-45 years who delivered between 2008 and 2012 in public hospitals. Women were enrolled through the Regional Birth Register. After linking the regional Health Information Systems and the Regional Drug Claims Register, women's clinical data and prescribed medications were analyzed. Italian Medicine Agency (AIFA) and US Food and Drug Administration (FDA) evidence were used to investigate inappropriate prescribing and teratogenic risk.
\end{abstract}

Results: Excluding vitamins and minerals, $80.6 \%(n=153,079)$ of the women were prescribed at least one drug during pregnancy, with an average of 4.6 medications per pregnancy. Drugs for blood and hematopoietic organs were the most commonly prescribed $(53.0 \%)$, followed by anti-infectives for systemic use (50.7\%). Among the inappropriate prescriptions, progestogen supplementation was given in $20.1 \%$ of pregnancies; teratogen drugs were prescribed in $0.8 \%$, mostly angiotensin co-enzyme inhibitors (ACEls) and angiotensin receptor blockers (ARBs) (0.3\%).

Conclusions: In Latium, drugs are widely used in pregnancy. Prescriptions of inappropriate drugs are observed in more than a fifth of pregnancies, and teratogens are still used, despite their known risk. Continuous updates of information provided to practitioners and an increased availability of information to women might reduce inappropriate prescribing.

Keywords: Inappropriate prescribing, Teratogens, Pregnancy, Health information system, Italy

\section{Background}

Women may need to take drugs during pregnancy for pre-existing health problems (e.g. diabetes), conditions occurring during pregnancy (e.g. infections) or for pregnancy-related complications (e.g. gestational hypertension). However, information about the efficacy and safety of drugs in pregnancy is very limited because pregnant women are hardly ever included in drug clinical trials, mainly for ethical reasons [1]. Medication safety information in pregnancy is therefore obtained through case reports, observational studies and animal studies [2, 3], all of which have limitations, making the

\footnotetext{
* Correspondence: m.ventura@deplazio.it

${ }^{1}$ Department of Epidemiology, Latium Regional Health Servigce, Via

Cristoforo Colombo, 112, 00147 Rome, Italy

Full list of author information is available at the end of the article
}

risk assessment of drug use during pregnancy difficult. All drugs should therefore be prescribed by assessing risks of medication against benefits of treatment on mother and fetus. It has been documented that congenital abnormalities caused by human teratogenic drugs account for less than $1 \%$ of total congenital abnormalities [4]. To evaluate the teratogenic or fetotoxic risks associated with drugs, different classifications systems based on data from human and animal studies have been developed. The US Food and Drug Administration (FDA) introduced the most well known classification in 1979 [5]. Medical associations have developed guidelines for the use of certain drugs during pregnancy including specific conditions or medication types [6, 7]. The EU-funded Seventh Framework Programme EUROmediCAT has developed a system to identify post market

(c) The Author(s). 2018 Open Access This article is distributed under the terms of the Creative Commons Attribution 4.0 International License (http://creativecommons.org/licenses/by/4.0/), which permits unrestricted use, distribution, and 
medications at the earliest possible stage that could increase teratogenicity. The program focused on risk assessment of congenital anomalies related to antiepileptics, insulin analogues, anti-asthmatics and antidepressant (SSRIs) and set out clinical recommendations [8]. In Italy, in 2005 the Ministry of Health appointed a panel of experts to release a clinical guideline on potential risks of drugs taken by mothers before and during pregnancy [9]. However, prescribing patterns continue to change over time as well as maternal characteristics such as age, prepregnancy BMI and clinical features. Therefore, prescribing contraindicated drugs to pregnant women is of great concern among clinicians and other obstetric health professionals. Intercountry comparability between studies on medication use in pregnancy is difficult due to dissimilarities in study design and methodology. A systematic review of recent literature on prescription drug use in countries with advanced health systems estimated that the number of pregnant women with at least one prescription, excluding vitamins and minerals, ranged from 44 to $93 \%$ [10]. A cross-sectional, multinational web-based study on the drug consumption in pregnant women showed that approximately 8 out of 10 women reported the use of at least one medication, either prescribed or over the counter, during the course of their pregnancy [11]. Studies providing additional information and updates on the use and appropriateness of medical drug consumption during pregnancy are of pivotal importance for women who are or are planning to become pregnant, for health care providers and for the society. So far, a limited number of studies has examined the use of prescription drugs among pregnant women in Italy [12-15]. The objective of this population-based study is the analysis of drug prescribing among pregnant women in Latium with specific regard to inappropriate and potentially or known teratogenic drugs.

\section{Methods}

A cross-sectional population study was conducted using data available in the regional Health Information Systems, specifically the Regional Birth Register (CeDAP), the Hospital Information System (HIS) and the Regional Drug Claims Register (PHARM). Data from different information systems were combined using a deterministic record-linkage procedure based on anonymous identification codes, which is a procedure in line with privacy legislation.

All women residing in Latium aged 18-45 years, who delivered in the regional birth units from the 1st of January 2008 to the 31st of December 2012, were enrolled through CeDAP. Socio-demographic characteristics and clinical information related to pregnancy and to previous hospitalizations were collected from HIS. Drug prescriptions were retrieved from PHARM. This Register contains data on all drugs, reimbursable by the National
Health Service, dispensed to residents in public and private pharmacies belonging to the regional health authorities. These drugs account for the majority of drugs used for acute or chronic conditions. Drugs administered during hospital stays are not registered. Data collection included information on the active agents and the exact quantification of the dispensed drug during pregnancy. We used the World Health Organization (WHO) Anatomical Therapeutic Chemical Classification System (ATC coding) to classify drugs, considering large anatomical groups, chemical groups (ATC fourth level) and single active agents (ATC fifth level) [16]. The gestational age at birth in completed weeks was retrieved by CeDAP, where it is routinely collected on the basis of the last menstrual period. In line with a study performed by Pisa et al., pregnancy trimesters were defined to assign etiologically relevant "time windows" of exposure to medication at the exact gestational age [17]. For each trimester, start and end dates were calculated backwards from the date of delivery and inferring the total pregnancy duration in days from the gestational age at birth.

Among women who gave birth more than once during the study-period, only information on medicines prescribed during the first pregnancy were recorded. Moreover, drugs prescribed only once during the first two months of pregnancy were excluded from the analysis, to avoid taking into account medications prescribed when the woman was not yet aware of being pregnant, and thus better assess the appropriateness of prescriptions in an ascertained pregnancy.

The main analysis focused on the drug prescription patterns in pregnancy. Analysis of drug prevalence was conducted both over the entire pregnancy and by trimester. Potential teratogens or potentially inappropriate drugs were assessed according to FDA and Italian Medicines Agency (AIFA) warnings by trimesters [5, 9]. The AIFA guide on drugs in pregnancy was considered as a reference document for Italian prescribers. A comparative analysis of the prescriptive behaviours before and during pregnancy was carried out for specific ATC groups.

Two logistic regression models were used: the first to model binary outcomes of potential inappropriate and teratogenic prescriptions, and the second to focus on inappropriate progestogen prescriptions. Model results were presented as odds ratios (OR) and their corresponding 95\% confidence intervals (CIs). The independent variables included in the models were mother's socio-demographic characteristics (age, nationality and education), parity, multiple pregnancy, previous miscarriages, comorbidities identified through HIS during the hospitalization for delivery and all hospital admissions in the previous two years. Comorbidities were first selected on the basis of a priori knowledge of clinical characteristics associated with 
outcomes and then grouped in a summary measure of severity.

The present study was funded by the Latium Region Pharmacovigilance call 2011 and was authorised by the ethics committee of the National Institute of Health.

\section{Results}

During the five-year study period we identified 189,923 deliveries, $61.2 \%$ of women were primiparous and $92.7 \%$ of pregnancies ended at term. Slightly less than $40 \%$ of the mothers were older than 34 years and $89.6 \%$ were Italian citizens. The majority of women had an education of more than eight years of school (71.9\%) (Table 1).

Excluding vitamins and minerals, $80.6 \%(n=153,079)$ of the women were prescribed at least one drug during pregnancy, with a prevalence of $53.3,57.4$ and $49.1 \%$ by trimester, respectively. The average of medication prescriptions was 4.6 during the overall pregnancy and in almost half of the population, more than three prescriptions were registered (data not shown). The most frequently prescribed agents were drugs for blood and hematopoietic organs $(53.0 \%, n=100,663)$, with folic acid prescribed in $37 \%$ and iron in $26.3 \%$ of women, followed by antiinfectives for systemic use $(50.7 \%, n=96,251)$. Among anti-infective prescriptions, erythromycin was prescribed in $27.6 \%$, amoxicillin in $13.5 \%$, penicillin in $10.2 \%$ and tetracycline in $0.2 \%$ (Table 2 ).

Overall, during pregnancy 44,303 women (23.3\%) received potentially inappropriate clinical prescriptions, and 1420 women $(0.8 \%)$ prescriptions of known or potential teratogens.

Among the group of clinically inappropriate drugs, progestogens were the most frequently prescribed (20.1\%) (Table 3), particularly during the first trimester of pregnancy $(17.1 \%)$, followed by glucocorticoids for systemic use (2.4\%), propionic acid derivates (1.3\%) and antiinflammatory and anti-rheumatic drugs (1.2\%) (Table 3).

Among drugs defined as potentially teratogenic the most frequently prescribed were ACE-inhibitors (ACEIs) and ARBs or combinations (0.27\%), followed by HMGCoA reductase inhibitors $(0.16 \%)$ and barbiturates and derivatives $(0.10 \%)$, fatty acid derivatives $(0.09 \%)$ and benzodiazepine derivatives $(0.07 \%)$ (Table 3$)$.

In a supplementary analysis focusing on antihypertensive drugs, we distinguished between prevalent and incident use of ACEIs/ARBs. Among the 3967 incident users, 550 started antihypertensive treatment during pregnancy. Of the 1446 women who had been taking ACEIs/ARBs before conception, 59.5\% $(n=861)$ suspended the therapy, $25.9 \%$ shifted to alternative appropriate antihypertensive medications and $14.6 \%(n=211)$ continued treatment with the teratogenic drug during pregnancy (data not shown).

Focusing on antiepileptic prescriptions $(n=898$ women), we found that the mostly prescribed agents were carbamazepine, phenobarbital, valproic acid, clonazepam and lamotrigine. Two hundred and thirty four women were prescribed more than one antiepileptic drug (polytherapy) before pregnancy. Among these, 37\%

Table 1 Women's socio-demographic and clinical characteristics

\begin{tabular}{|c|c|c|c|}
\hline & & Number & Percent \\
\hline \multirow[t]{5}{*}{ Age at delivery (years) } & $<=24$ & 13,483 & 7.1 \\
\hline & $25-29$ & 36,524 & 19.2 \\
\hline & $30-34$ & 67,665 & 35.6 \\
\hline & $35-39$ & 56,622 & 29.8 \\
\hline & $>=40$ & 15,629 & 8.2 \\
\hline \multirow[t]{2}{*}{ Nationality } & Italian & 170,161 & 89.6 \\
\hline & Other & 19,762 & 10.4 \\
\hline \multirow[t]{4}{*}{ Level of education ${ }^{a}$} & None or Elementary school ( $<=5$ years) & 9777 & 5.1 \\
\hline & Middle school (8 years) & 42,535 & 22.4 \\
\hline & High school (12-13 years) & 97,271 & 51.2 \\
\hline & Bachelor degree (> 13 years) & 39,309 & 20.7 \\
\hline \multirow[t]{3}{*}{ Gestagional age } & Preterm (<37 weeks) & 13,289 & 7.0 \\
\hline & Full-term (37 e 42 weeks) & 176,103 & 92.7 \\
\hline & Post-term (> 42 weeks) & 531 & 0.3 \\
\hline \multirow[t]{3}{*}{ Parity $^{a}$} & 0 & 116,144 & 61.1 \\
\hline & 1 & 58,587 & 30.8 \\
\hline & $\geq 2$ & 15,175 & 8.0 \\
\hline
\end{tabular}

${ }^{\mathrm{a}}$ The percentages may not sum $100 \%$ due to missing data 
Table 2 Women with at least one prescription during pregnancy: prescribed drugs according to ATC classification

\begin{tabular}{|c|c|c|c|}
\hline \multirow[t]{2}{*}{ Drug groups } & \multirow[t]{2}{*}{ ATC } & \multicolumn{2}{|c|}{ Overall pregnancy } \\
\hline & & $\mathrm{N}$ & $\%$ \\
\hline \multicolumn{4}{|l|}{ Anatomical groups } \\
\hline Alimentary Tract and Metabolism & A & 22,800 & 12.00 \\
\hline Blood and Blood Forming Organs & B & 100,663 & 53.00 \\
\hline Cardiovascular System & $\mathrm{C}$ & 5855 & 3.08 \\
\hline Dermatologicals & $\mathrm{D}$ & 719 & 0.38 \\
\hline Genito Urinary System and Sex Hormones & G & 41,178 & 21.68 \\
\hline Systemic Hormonal Preparations, excl.Sex Hormones and Insulins & $\mathrm{H}$ & 21,037 & 11.08 \\
\hline Antiinfectives for Systemic Use & J & 96,251 & 50.68 \\
\hline Antineoplastic and Immunomodulating Agents & $L$ & 244 & 0.13 \\
\hline Muscolo-Skeletal System & M & 6291 & 3.31 \\
\hline Nervous System & $\mathrm{N}$ & 3091 & 1.63 \\
\hline Respiratory System & $\mathrm{R}$ & 17,273 & 9.09 \\
\hline Sensory Organs & $S$ & 301 & 0.16 \\
\hline \multicolumn{4}{|l|}{ Chemical subgroups (most prescribed) } \\
\hline Folic acid and derivatives & $\mathrm{B} 03 \mathrm{BB}$ & 70,116 & 36,9 \\
\hline Macrolides & J01FA & 52,438 & 27,6 \\
\hline Iron bivalent, oral preparations & B03AA & 47,175 & 24,8 \\
\hline Pregnen derivatives & G03DA & 38,834 & 20,4 \\
\hline Penicillins with extended spectrum & J01CA & 25,581 & 13,5 \\
\hline Heparin group & $B 01 A B$ & 15,473 & 8,1 \\
\hline Thyroid hormones & H03AA & 14,002 & 7,4 \\
\hline Glucocorticoids - respiratory & R03BA & 12,587 & 6,6 \\
\hline Glucocorticoids - systemic & $\mathrm{H} 02 \mathrm{AB}$ & 8215 & 4,3 \\
\hline
\end{tabular}

( $\mathrm{n}=86)$ changed polytherapy treatment to monotherapy. Of the 204 women using high doses of antiepileptics before pregnancy, $42 \%$ reduced the dose after conception (data not shown).

Three logistic regression models showed factors associated with potential inappropriate, teratogenic and progestogen drug prescriptions, for which there is no scientific evidence for a benefit (Table 4). Maternal age $\geq$ 35 years and presence of comorbidities increased the risk of all three outcomes. Multiple pregnancies and previous miscarriage augmented the risk of inappropriate drugs and, particularly progestogen prescriptions. On the contrary, multiparity and high educational level were significantly protective factors for all potential inappropriate and teratogenic prescriptions investigated. Italian women had a higher risk of receiving progestogen prescriptions than foreigners (Table 4).

\section{Discussion}

The estimated rate of drug prescriptions in pregnancy among women delivering in Latium from 2008 to 2012 was $81 \%$ excluding vitamin and minerals. To our knowledge the only two other population-based studies conducted in 2004 and in 2011 in two regions of northern Italy $[13,15]$ reported respectively 48,3 and $72,7 \%$ of antenatal prescriptions.

In developed countries the use of prescription medicines is widespread, but comparisons are difficult due to differences in methods and reporting of drug utilization. A systematic review published from 1989 to 2010 reported a wide variation in estimates of overall antenatal drug prescriptions, ranging from 27 to $93 \%$. Among the most comparable European studies using administrative prescription databases, Northern Europe reported the lowest rates of prescriptions ranging from 44.2 to $57 \%$. The highest rates were found in the Netherlands (69.2\%) , Germany (85.2\%) and France (93\%) [10].

In our study, the most frequently prescribed agents were drugs for blood and hematopoietic organs (53\%) with folic acid prescribed in $37 \%$. This proportion underestimates the real consumption because in Italy folic acid is available as an over the counter drug. A knowledge, attitude and practice survey investigating the use of folic acid and its appropriateness among a sample of 562 women who delivered in Latium region between 2013 and 2014 [18] reported 95\% of women had taken 
Table 3 Prevalence of potential inappropriate/teratogen prescriptions during pregnancy according to trimesters at risk and ATC

\begin{tabular}{|c|c|c|c|c|}
\hline Potential inappropriate drugs & ATC & Trimester at risk & $N^{a}$ & $\%$ \\
\hline Total & & & 44,303 & 23.33 \\
\hline Progestogens & G03D & $1-2$ & 38,146 & 20.09 \\
\hline Glucocorticoids for systemic use & $\mathrm{H} 02 \mathrm{AB}$ & 1 & 4458 & 2.35 \\
\hline Propionic acid derivates (Ibuprofen, Naproxen, Ketoprofen) & M01AE01-03 & $1-3$ & 2495 & 1.31 \\
\hline Anti-inflammatory and antirheumatic & M01AX & $1-3$ & 2203 & 1.16 \\
\hline Acetic acid derivatives and related substances (excluding Indomethacin) & M01AB (exc M01AB01) & $1-3$ & 1461 & 0.77 \\
\hline Oxicams & M01 AC & $1-3$ & 200 & 0.11 \\
\hline Bile acid sequestrants & C10AC & $1-3$ & 191 & 0.10 \\
\hline Coxib & $\mathrm{M} 01 \mathrm{AH}$ & $1-2$ & 40 & 0.02 \\
\hline Antigonadotropins and similar agents & G03XA & $1-2$ & 8 & 0.00 \\
\hline Indomethacin & M01AB01 & $1-2$ & 8 & 0.00 \\
\hline Ezetimibe & C10AX09 & $1-3$ & 1 & 0.00 \\
\hline Nicotinic acid and its derivatives & C10AD & $1-3$ & 0 & 0.00 \\
\hline Known or potential teratogen drugs & ATC & Trimester at risk & $N^{a}$ & $\%$ \\
\hline Total & & & 1420 & 0.78 \\
\hline ACE-inhibitors, ARBs or combinations & C09 & $2-3$ & 508 & 0.27 \\
\hline HMG-CoA reductase inhibitors (statins) & C10AA,C10B & $1-3$ & 297 & 0.16 \\
\hline Barbiturates and derivatives & N03AA & $1-3$ & 199 & 0.10 \\
\hline Fatty acid derivatives & N03AG & $1-3$ & 177 & 0.09 \\
\hline Benzodiazepine derivatives & NO3AE & $1-3$ & 132 & 0.07 \\
\hline Tetracycline & J01AA & 3 & 91 & 0.05 \\
\hline Imidazole and its derivatives (Thiamazole) & H03BB02 & 1 & 48 & 0.03 \\
\hline Triazole and its derivatives (Fluconazole) & J02AC01 & 1 & 16 & 0.01 \\
\hline Lithium & N05AN01 & $1-3$ & 16 & 0.01 \\
\hline Vitamin $\mathrm{K}$ antagonists & B01AA & $1-3$ & 13 & 0.01 \\
\hline Anti-arrhythmic drugs class III (Amiodarone) & C01BD01 & $1-3$ & 9 & 0.00 \\
\hline Retinoids for acne treatment & D10BA01 & 1 & 4 & 0.00 \\
\hline Penicillamine and similar agents & M01CC & $1-3$ & 3 & 0.00 \\
\hline Retinoids for psoriasis treatment & D05BB & $1-3$ & 2 & 0.00 \\
\hline
\end{tabular}

${ }^{a}$ women with at least one prescription

folic acid during pregnancy. In line with the increase $(13 \%)$ in antibiotic consumption registered in the Italian general population in the years 1999-2007, in our study $50 \%$ of the participating women took antibiotics during pregnancy [19]. This proportion is higher compared to other population-based studies in European settings ranging from 27 to $32 \%$ [20-22] and similar to a French study where $42 \%$ of pregnant women were exposed to antimicrobials [23]. The previous Italian studies reported respectively 37.2 and $24.8 \%$ of women prescribed with antibiotics during pregnancy $[13,15]$. Given the growing problem of bacterial resistance, an increase in the use of antibiotics during pregnancy requires careful thought in terms of prescriptive appropriateness [24]. Therefore, it is urgent to understand the motivation for the high antimicrobial prescription rate in Latium. The most likely patients to be prescribed these drugs were women aged over 40 representing $8 \%$ of the total cohort, and those who had comorbidities during hospitalizations in the previous two years (data not shown).

The frequent prescribing of progestogens (21.2\%) during the first and second trimester of pregnancy detected in Latium is worthy of attention. In 2009, the World Health Organization recommended not to prescribe progestogens for preventing miscarriages. A Cochrane review updated in 2013 [25], including respectively 14 RCTs (2158 women), concluded that progestogen is ineffective for the treatment of threatened abortion except in women with a history of three or more previous miscarriages. On the other hand, a more recent randomized 
Table 4 Factors associated with potential inappropriate, teratogen, progestogen drug prescriptions during pregnancy

\begin{tabular}{|c|c|c|c|c|c|c|c|c|c|c|c|}
\hline & & \multicolumn{3}{|c|}{$\begin{array}{l}\text { Inappropriate drug } \\
\text { prescriptions }{ }^{a}\end{array}$} & \multicolumn{3}{|c|}{$\begin{array}{l}\text { Teratogen drug } \\
\text { prescriptions }\end{array}$} & \multicolumn{4}{|c|}{$\begin{array}{l}\text { Progestogen drug } \\
\text { prescriptions }\end{array}$} \\
\hline & & $\%$ & OR adj & IC 95\% (inf-sup) & $\%$ & OR adj & IC 95\% (inf-sup) & $\%$ & OR adj & $\begin{array}{l}\text { IC } 950 \\
\text { sup) }\end{array}$ & 0 (inf- \\
\hline \multicolumn{12}{|l|}{ Socio-demographic variables } \\
\hline \multirow[t]{3}{*}{ Age classes } & $\leq 34$ & 5.4 & 1 & & 0.7 & 1 & & 15.8 & 1 & & \\
\hline & $35-39$ & 7.8 & 1.54 & $1.47-1.61$ & 0.9 & 1.45 & $1.29-1.64$ & 25.4 & 1.88 & 1.83 & 1.92 \\
\hline & $\geq 40$ & 11.4 & 2.23 & $2.08-2.38$ & 1.2 & 1.99 & $1.68-2.35$ & 33.5 & 2.68 & 2.58 & 2.79 \\
\hline \multirow[t]{2}{*}{ Nationality } & Other & 6.4 & 1 & & 0.8 & 1 & & 12.9 & 1 & & \\
\hline & Italian & 6.5 & 0.95 & $0.89-1.01$ & 0.8 & 0.97 & $0.81-1.15$ & 20.9 & 1.52 & 1.46 & 1.59 \\
\hline \multirow[t]{4}{*}{ Education } & None/elementary school & 7.7 & 1 & & 1.1 & 1 & & 20.3 & 1 & & \\
\hline & Middle school & 6.9 & 0.99 & $0.90-1.08$ & 0.8 & 0.79 & $0.63-0.98$ & 17.8 & 0.99 & 0.93 & 1.05 \\
\hline & High school & 6.5 & 0.86 & $0.79-0.94$ & 0.8 & 0.67 & $0.55-0.83$ & 20.4 & 1.04 & 0.99 & 1.10 \\
\hline & Bachelor degree & 5.9 & 0.72 & $0.65-0.79$ & 0.7 & 0.57 & $0.45-0.72$ & 21.8 & 0.97 & 0.92 & 1.02 \\
\hline \multicolumn{12}{|l|}{ Other variables } \\
\hline \multirow[t]{2}{*}{ Multiple pregnancies } & No & 6.3 & 1 & & 0.8 & 1 & & 19.5 & 1 & & \\
\hline & Yes & 21.1 & 3.75 & $3.37-4.17$ & 0.9 & 1.03 & $0.71-1.50$ & 50.9 & 3.91 & 3.65 & 4.19 \\
\hline \multirow[t]{2}{*}{ Parity } & Primiparous & 6.7 & 1 & & 0.8 & 1 & & 21.9 & 1 & & \\
\hline & Multiparous & 6.2 & 0.77 & $0.74-0.81$ & 0.8 & 0.85 & $0.76-0.95$ & 17.3 & 0.63 & 0.61 & 0.64 \\
\hline \multirow{2}{*}{$\begin{array}{l}\text { Previous miscarriages ( } 10 \text { years } \\
\text { before) }\end{array}$} & None & 6.1 & 1 & & 0.8 & 1 & & 18.7 & 1 & & \\
\hline & At least one & 12.5 & 2.02 & $1.90-2.15$ & 0.8 & 0.91 & $0.75-1.11$ & 35.3 & 2.19 & 2.11 & 2.27 \\
\hline \multicolumn{12}{|l|}{ Comorbidities $^{b}$} \\
\hline \multirow[t]{3}{*}{ Comorbidities } & None & 6.4 & 1 & & 0.7 & 1 & & 19.9 & 1 & & \\
\hline & 1 & 10.3 & 1.57 & $1.44-1.71$ & 1.5 & 2.06 & $1.68-2.51$ & 24.4 & 1.18 & 1.11 & 1.24 \\
\hline & $\geq 2$ & 16.1 & 2.63 & $2.06-3.36$ & 4.5 & 6.15 & 4.13-9.15 & 26.4 & 1.28 & 1.07 & 1.54 \\
\hline
\end{tabular}

awomen who had only progestogen prescriptions were not considered

banemia, coagulation defects, cardiovascular disorders, congenital heart defects, congenital malformations of circulatory system; cerebrovascular disorders nephritis, nephrotic syndrome, and nephrosis; collagen diseases, HIV seropositive/AIDS; thyroid diseases; diabetes, hypertension, chronic obstructive pulmonary disease, asthma, cystic fibrosis, chronic pneumonia

trial in which progestogen had been administered during the first trimester of pregnancy did not result in a significant increase in the rate of live births even among women with a history of unexplained recurrent miscarriages [26]. The evidence that progestogen is ineffective in lowering the risk of miscarriages and the persistence of this inappropriate prescriptive habit in Italy bolsters the importance of clinical recommendations to avoid unnecessary medication overuse which increases public spending .

Seven studies included in the Canadian systematic review reported the use of drugs recognized as having potential risks for fetal harm in pregnancy, as classified by the FDA, ranging from 0,9 to $4,6 \%$ [10]. In the present study, the percentage of pregnancies exposed to known or potential teratogens was $0.7 \%$.

Antihypertensive drugs such as ACE inhibitors and ARBs are extremely effective in lowering blood pressure and offer significant benefits in proteinuric diseases. Their use during the second and third trimesters is contraindicated by FDA because their in utero effect is associated with fetal renal dysplasia, anuria and kidney failure, and even fetal death [27-29]. In our study ACE inhibitors and ARBs were prescribed in $0.3 \%$ of the Latium cohort, showing rather similar prescribing patterns as compared to those reported in Lombardia between 2009 and 2010 [14]. Hence, prenatal counseling in women with chronic hypertension is an important component of their care. Women should be advised on the importance of birth control while on these drugs and should promptly suspend their intake in case of pregnancy, switching to a safe antihypertensive therapy in case dietary restrictions are ineffective in controlling blood pressure.

Among drugs defined as known or potential teratogens, the ATC group of anti-epileptics deserves different considerations because interruption of the treatment could pose even greater risk for both the mother and the fetus. Recommended solutions include switching from combination to monotherapy and prescribing the minimum effective dosage. In our study, $37 \%$ of women switched from polytherapy to monotherapy and $42 \%$ 
reduced their dose, suggesting that clinicians were aware of the appropriate clinical practice.

Multivariate data analysis (Table 4) assessed a lower risk of receiving inappropriate and teratogenic prescriptions during pregnancy among highly educated and multiparous mothers probably due to their greater "empowerment" compared to lesser educated women and first-time mothers. Contrarily, one or more previous comorbidities and maternal age $\geq 35$ years were significantly associated with a higher risk of potential inappropriate and teratogenic prescriptions. As more women delay childbearing in Italy, where the proportion of delivering women $\geq 35$ years rose from $9 \%$ in 1981 to $35 \%$ in 2014 , advanced maternal age is a challenge for the health system.

The logistic regression investigating risk factors for clinically inappropriate prescribing gave evidence that multiple pregnancies and a history of previous miscarriage are associated with an almost four times higher risk of inappropriate and teratogenic prescriptions compared to singleton pregnancies, and to a double risk compared to women without previous miscarriages. On the contrary, multiparous women were found to be at lower risk of inappropriate, teratogenic and progestogen prescriptions. We discussed these findings with a panel of gynecologists, general practitioners, and midwives, and they suggested that multiparous women may be more experienced and better informed compared to nulliparae and therefore, less likely to overuse medicalization that characterizes pregnancy care in Italy.

There are some limitations to be mentioned: betweencountry comparison may be biased by different drug reimbursement policies, i.e. some drugs that are not refunded in Italy might be refunded in other countries and vice versa. The present results refer to one Italian region and may not be representative of other parts of Italy.

Furthermore, using administrative data, drug use may be prone to imprecisions in either direction, over- and under-estimation: our data do not include over-the-counter drugs or drugs which are not refunded by the health care system. On the other hand, drug use could be overestimated, in case the drug is claimed in the pharmacy but not actually taken by the woman. Previous investigations have shown a good capacity of the Italian health information systems to capture medications used chronically, whereas drugs used sporadically may be underestimated or not correctly allocated in time (e.g. in Italy, antibiotics are usually stocked at home and taken as needed, which means that the user and the time of use may not match with the purchaser and the time of the drug claims registered in our administrative data). This observation is in line with results reported in Canada [30], the Netherlands [31] and the US [32]. A recent
Italian study comparing administrative data with maternal self-reports on drug use in pregnancy found a high agreement for medications used for chronic conditions. The authors also investigated the quality of information retrieved from administrative data on gestational age and found birth certificates to be a reliable source of information on the timing of pregnancy [17]. Moreover, misclassification associated to socio-economic differences can be ruled out as shown in a previous study which gave evidence for equal access in our health care system [33]. Unfortunately our database does not provide information on indications for prescribing, and consequently we were not able to investigate the use of these drugs more in depth. Finally, the present study could not include pregnancies ending in spontaneous and therapeutic abortions, because they are not retrievable in the database. This limitation introduces a likely underestimation of drug prescribing with a potential for fetal harm. On the other hand, the population based approach, the record-linkage of administrative databases and the large cohort enrolled are strong points of the study, allowing robust data analysis reinforced by the sensitivity analysis for determining the prescription patterns.

Previously, four studies on this topic were performed in Italy. However, one referred to a population survey including a sample of Italian women and contained only a few questions on drug use [12], and a second one was an investigation focusing on antihypertensive drug use in pregnancy [14]. The two population-based studies using administrative data were conducted in northern Italy $[13,15]$ and may not be representative of other Italian contexts and geographical areas and this was a motivation to conduct the study in Latium. It has been previously shown that between Italian geographical areas and regions there is a considerable variability in the prevalence of drug consumption during pregnancy. For example, the consumption of folic acid during the periconceptional period varied between 0.0 and $40.0 \%$ and between 7.1 and $39.5 \%$ according to different geographical areas in two wide multi-centric population based surveys [34, 35]. Therefore, this is the first populationbased study in a region located in central Italy, evaluating prescription drugs in detail during pregnancy in recent years.

In Latium, drugs are widely used in pregnancy and the present study highlights the necessity of specific interventions in three distinct areas; first, the periodic collection of data regarding drug prescribing during pregnancy; second, the continuous update of information provided to practitioners (specifically general practitioners and gynecologists); and third, the increased availability of information to women and the public. In view of the evident differences based on the womens' 
educational level, reducing inequities in access to information and drug prescribing is a matter of priority.

This project can be considered a pilot study able to detect and investigate the critical aspects of drug prescribing in pregnancy in a large Italian cohort of pregnant women. The adopted method could be periodically replicated in different regions of the country with the objective of monitoring prescription patterns in pregnancy, and make recommendations to prevent prescriptions of potential teratogens and clinically inappropriate drugs. Our study is in line with the objectives of EUROmediCAT project, which plans to build a European system that allows evaluating the safety of drug use during pregnancy.

\section{Conclusions}

Drug prescriptions during pregnancy in Latium are very common. Consumption of potential teratogens and clinically inappropriate drugs was low but not absent. Continuous update of information provided to practitioners, and an increased availability of information to women and the public may help to further reduce the risk of inappropriate prescribing during pregnancy.

\begin{abstract}
Abbreviations
ACEl: Angiotensin Co-Enzyme Inhibitor; AIFA: Agenzia Italiana del Farmaco; ARB: Angiotensin Receptor Blocker; ATC: Anatomical Therapeutic Chemical Classification; BMI: Body Mass Index; CeDAP: Certificato di Assistenza al Parto; Cl: Confidence Interval; EU: European Union; FDA: Food and Drug Administration; HIS: Hospital Information System; OR: Odds Ratio; PHARM: Regional Drug Claims Register; RCT: Randomized Controlled Trial; SSRI: Selective serotonin reuptake inhibitor; WHO: World Health Organization
\end{abstract}

\section{Acknowledgements}

We are grateful to Vincenzo Scotto di Palumbo, MD, Francesco Maneschi, MD, Paola Casolini, MD, and Marina Moscatelli, MD, for the useful comments in the data analysis and the interpretation of the results and to Silvia Andreozzi for editing the manuscript.

\section{Ethics approval and consent to partecipate}

This study was carried out in full compliance with the current privacy laws and was authorised by the ethics committee of the National Institute of Health. The Department of Epidemiology is authorized by the Lazio Regional Committee to manage and analyze data from the regional health information systems for epidemiological purposes.

\section{Funding}

The present study was funded by the Latium Region Pharmacovigilance call 2011.

\section{Availability of data and materials}

The data used for the study are not openly available. The study was conducted with the permission of the Department of Epidemiology of Lazio Regional Health Service, the regional referral centre of epidemiological research which has full access to anonymized health information systems. The Department of Epidemiology has been authorised by the Regional Health Authority to use the data.

\section{Authors' contributions}

SD conceived the idea of the study and together with UK were responsible for the design of the study. MV was responsible for the acquisition of the data. MV and AM were responsible for undertaking the data analysis and produced the tables and graphs. SD, UK and IL provided input into the data analysis. UK, SD, MD, IL, PDA contributed to the interpretation of the results.
The manuscript was drafted by MV, AM, PDA, UK, and SD and then shared with all authors for critical revision. All authors read and approved the final manuscript.

\section{Competing interests}

The authors declare that they have no competing interests.

\section{Publisher's Note}

Springer Nature remains neutral with regard to jurisdictional claims in published maps and institutional affiliations.

\section{Author details}

${ }^{1}$ Department of Epidemiology, Latium Regional Health Servigce, Via Cristoforo Colombo, 112, 00147 Rome, Italy. ${ }^{2}$ National Centre for Diseases Prevention and Health Promotion, Rome, Italy.

Received: 5 May 2017 Accepted: 4 May 2018

Published online: 15 May 2018

References

1. Shivayogi P. Vulnerable population and methods for their safeguard. Perspect Clin Res. 2013:4(1):53-7.

2. Adam MP, Polifka JE, Friedman JM. Evolving knowledge of the teratogenicity of medications in human pregnancy. Am J Med Genet C Semin Med Genet. 2011;157C(3):175-82.

3. Thorpe PG, Gilboa SM, Hernandez-Diaz S, et al. Medications in the first trimester of pregnancy: most common exposures and critical gaps in understanding fetal risk. Pharmacoepidemiol Drug Saf. 2013;22(9):1013-8. https://doi.org/10.1002/pds.3495.

4. Sachdeva P, Patel BG, Patel BK. Drug use in pregnancy; a point to ponder! Indian J Pharm Sci. 2009:71(1):1-7.

5. FDA Pregnancy and Lactation Labeling (Drugs). http://www.fda.gov/Drugs/ DevelopmentApprovalProcess/DevelopmentResources/Labeling/ucm093307. htm. Accessed 10 Dec 2011.

6. American College of Obstetricians Gynecologists Committee on Obstetric Practice. ACOG committee opinion no. 494: sulfonamides, nitrofurantoin, and risk of birth defects. Obstet Gynecol. 2011;117(6):1484-5.

7. Harden $\mathrm{CL}$, Meador KJ, Pennell PB, et al. Management issues for women with epilepsy-focus on pregnancy (an evidence-based review): II. Teratogenesis and perinatal outcomes: report of the quality standards subcommittee and therapeutics and Technology Subcommittee of the American Academy of neurology and the American Epilepsy Society. Epilepsia. 2009;50(5):1237-46.

8. Euromedicat. Medication safety in pregnancy. http://www.euromedicat.eu/. Accessed 12 Jan 2012

9. Italian Medicine Agency (AIFA). Pregnancy and drugs. http://www. farmaciegravidanza.gov.it. Accessed 12 Mar 2012.

10. Daw JR, Hanley GE, Greyson DL, Morgan SG. Prescription drug use during pregnancy in developed countries: a systematic review. Pharmacoepidemiol Drug Saf. 2011;20(9):895-902. https://doi.org/10.1002/pds.2184. Epub 2011 Jul 20. Review. PubMed PMID: 21774029; PubMed Central PMCID: PMC3423446

11. Lupattelli A, Spigset O, Twigg MJ, Zagorodnikova K, Mårdby AC, Moretti ME, Drozd M, Panchaud A, Hämeen Anttila K, Rieutord A, Gjergja Juraski R, Odalovic M, Kennedy D, Rudolf G, Juch H, Passier A, Björnsdóttir I, Nordeng $H$. Medication use in pregnancy: a cross-sectional, multinational web-based study. BMJ Open. 2014;4(2):e004365.

12. Donati S, Baglio G, Spinelli A, Grandolfo ME. Drug use in pregnancy among Italian women. Eur J Clin Pharmacol. 2000:56(4):323-8.

13. Gagne JJ, Maio V, Berghella V, Louis DZ, Gonnella JS. Prescription drug use during pregnancy: a population-based study in Regione Emilia-Romagna, Italy. Eur J Clin Pharmacol. 2008 Nov:64(11):1125-32.

14. D'Amore C, Trotta F, Da Cas R, Zocchetti C, Cocci A, Traversa G. Antihypertensive drug use during pregnancy: a population based study. Ann Ist Super Sanita. 2015;51(3):236-43. https://doi.org/10.4415/ANN_15 03 12. PubMed PMID:26428049

15. Valent F, Gongolo F, Deroma L, Zanier L. Prescription of systemic antibiotics during pregnancy in primary care in Friuli Venezia Giulia, northeastern Italy. J Matern Fetal Neonatal Med. 2015;28(2):210-5.

16. World Health Organization. Anatomical therapeutic classification: structure and principles. Oslo: World Health Organization; 2011. [Updated 2011 Mar 
25; cited 2014]. Accessed 12 Mar 2012. http://www.whocc.no/atc/structure_ and_principles/

17. Pisa FE, Casetta A, Clagnan E, Michelesio E, Vecchi Brumatti L, Barbone F. Medication use during pregnancy, gestational age and date of delivery: agreement between maternal self-reports and health database information in a cohort. BMC Pregnancy Childbirth. 2015;15:310.

18. Maraschini A, D'Aloja P, Lega I, Buoncristiano M, Kirchmayer U, Ventura M, Donati S. Do Italian pregnant women use periconceptional folate supplementation? Ann Ist Super Sanita. 2017;53(2):118-24. https://doi.org/ 10.4415/ANN_17_02_07. PubMed PMID: 28617257

19. Italian Medicine Agency (AIFA). Antibiotics. http://www.agenziafarmaco.gov. it/it/content/antibiotici. Accessed 12 Mar 2012.

20. Petersen I, Gillbert R, Evans S, Ridolfi A, Nazareth I. Oral antibiotic prescribing during pregnancy in primary care: UK population-based study. J Antimicrob Chemother. 2010;65(10):2238-46.

21. Engeland A, Bramness JG, Daltveit AK, Rønning M, Skurtveit S, Furu K. Prescription drug use among fathers and mothers before and during pregnancy. A population-based cohort study of 106,000 pregnancies in Norway 2004-2006. Br J Clin Pharmacol. 2008;65(5):653-60.

22. Romøren M, Lindbæk M, Nordeng H. Pregnancy outcome after gestational exposure to erythromycin - a population-based register study from Norway. Br J Clin Pharmacol. 2012;74(6):1053-62.

23. Lacroix I, Hurault C, Sarramon MF, Guitard C, Berrebi A, Grau M, AlbouyCossard C, Bourrel R, Elefant E, Montastruc JL, Damase-Michel C. Prescription of drugs during pregnancy: a study using EFEMERIS, the new French database. Eur J Clin Pharmacol. 2009:65(8):839-46.

24. Woon S-A, Fisher D. Antimicrobial agents - optimising the ecological balance. BMC Med. 2016;14:114. https://doi.org/10.1186/s12916-016-0661-z

25. Haas DM, Ramsey PS. Progestogen for preventing miscarriage. Cochrane Database Syst Rev. 2013;10:CD003511. https://doi.org/10.1002/14651858. CD003511.pub3. Review. PubMed PMID: 24173668

26. Coomarasamy A, Williams H, Truchanowicz E, Seed PT, Small R, Quenby S, Gupta P, Dawood F, Koot YE, Bender Atik R, Bloemenkamp KW, Brady R, Briley AL, Cavallaro R, Cheong YC, Chu JJ, Eapen A, Ewies A, Hoek A, Kaaijk EM, Koks CA, Li TC, MacLean M, Mol BW, Moore J, Ross JA, Sharpe L, Stewart J, Vaithilingam N, Farquharson RG, Kilby MD, Khalaf Y, Goddijn M, Regan L, Rai R. A randomized trial of progesterone in women with recurrent miscarriages. N Engl J Med. 2015;373(22):2141-8.

27. Cooper WO, Hernandez-Diaz S, Arbogast PG, Dudley JA, Dyer S, Gideon PS, Hall K, Ray WA. Major congenital malformations after first-trimester exposure to ACE inhibitors. N Engl J Med. 2006;354(23):2443-51.

28. Kattah AG, Garovic VD. The management of hypertension in pregnancy. Adv Chronic Kidney Dis. 2013;20(3):229-39.

29. Bateman BT, Patorno E, Desai RJ, Seely EW, Mogun H, Dejene SZ, Fischer MA, Friedman AM, Hernandez-Diaz S, Huybrechts KF. Angiotensinconverting enzyme inhibitors and the risk of congenital malformations. Obstet Gynecol. 2017;129(1):174-84.

30. Zhao JP, Sheehy O, Gorgui J, Bérard A. Can we rely on pharmacy claims databases to ascertain maternal use of medications during pregnancy? Birth Defects Res. 2017;109(6):423-31.

31. Cheung K, El Marroun H, Elfrink ME, Jaddoe WWV, Visser LE, Stricker BHC. The concordance between self-reported medication use and pharmacy records in pregnant women. Pharmacoepidemiol Drug Saf. 2017;25 https://doi.org/ 10.1002/pds.4264. [Epub ahead of print]

32. Sarangarm P, Young B, Rayburn W, Jaiswal P, Dodd M, Phelan S. Bakhireva L agreement between self-report and prescription data in medical records for pregnant women. Birth Defects Res A Clin Mol Teratol. 2012;94(3):153-61.

33. Kirchmayer U, Agabiti N, Belleudi V, Davoli M, Fusco D, Stafoggia M, Arcà M, Barone AP, Perucci CA. Socio-demographic differences in adherence to evidence-based drug therapy after hospital discharge from acute myocardial infarction: a population-based cohort study in Rome. Italy J Clin Pharm Ther. 2012;37(1):37-44. https://doi.org/10.1111/j.1365-2710.2010 01242.x. Epub 2011 Feb 6. PubMed PMID: 21294760

34. Lauria L, Andreozzi S. Percorso nascita e immigrazione in Italia: le indagini del 2009. Roma: Istituto Superiore di Sanità; 2011. (Rapporti ISTISAN 11/12)

35. Lauria L, Lamberti A, Buoncristiano M, Bonciani M, Andreozzi S. Percorso nascita: promozione e valutazione della qualità di modelli operativi. Le indagini del 2008-2009 e del 2010-2011. Roma: Istituto Superiore di Sanità; 2012. (Rapporti ISTISAN 12/39)

\section{Ready to submit your research? Choose BMC and benefit from:}

- fast, convenient online submission

- thorough peer review by experienced researchers in your field

- rapid publication on acceptance

- support for research data, including large and complex data types

- gold Open Access which fosters wider collaboration and increased citations

- maximum visibility for your research: over $100 \mathrm{M}$ website views per year

At BMC, research is always in progress.

Learn more biomedcentral.com/submissions 